\title{
Synergistic effect of $V$ and $M n$ oxyanions for the corrosion protection of anodized aerospace aluminum alloy
}

\author{
G. Yoganandan, J. N. Balaraju*, \\ Surface Engineering Division, CSIR National Aerospace Laboratories, Post Bag No. 1779 \\ Bangalore 560017, Karnataka, India
}

\begin{abstract}
Oxide layer was developed on AA2024 by using sulphuric acid anodization process. The $\mathrm{Mn}-\mathrm{V}$ oxyanions were successfully incorporated into the developed pores and cracks during the sealing process. Field emission scanning electron microscopy (FESEM) studies showed that the as-prepared specimen exhibited tortuous porous morphology. Energy dispersive X-ray (EDAX) results revealed that the incorporation of $\mathrm{V}$ was significantly high (11 at. \%) compared to $\mathrm{Mn}$ $(0.76$ at. $\%)$ in the case of $\mathrm{Mn}-\mathrm{V}$ oxyanions incorporated oxide layer. It also revealed the presence of $\mathrm{V}$ oxyanion in the sealing bath enhances the incorporation of $\mathrm{Mn}$ oxyanion. X-ray photoelectron and Raman spectroscopy results revealed that both $\mathrm{Mn}$ and $\mathrm{V}$ ions exist in different forms of oxides and hydroxides. Atomic force microscopy (AFM) results revealed that the incorporation of $\mathrm{Mn}-\mathrm{V}$ reduced the average roughness value of about 4.5 and 3.7 times compared to plain and only $\mathrm{Mn}$ incorporated oxide layers. The electrochemical impedance spectroscopy (EIS) and potentiodynamic polarization studies revealed that the $\mathrm{Mn}-\mathrm{V}$ incorporated oxide layer offered improved corrosion resistance up to $336 \mathrm{~h}$ of immersion into $3.5 \% \mathrm{NaCl}$ solution. Neutral salt spray exposure as per the ASTM B117 results showed that Mn$\mathrm{V}$ incorporated oxide layer could withstand more than $2000 \mathrm{~h}$. Plausible coating formation and inhibition mechanism had also been discussed based on the thorough investigation of the coatings before and after the corrosion reaction by different techniques.
\end{abstract}

Keywords: EIS; Anodization; Raman Spectroscopy; Corrosion; AA2024 alloy; XPS

* Corresponding author: jnbalraj@nal.res.in (J.N.Balaraju); Tel: 9180 25086239; Fax: 9180 25210113 


\subsection{Introduction}

The high strength aluminum alloy AA2024 and AA7075 are widely used in the aircraft industry due to its significantly improved mechanical properties [1]. The $\mathrm{Cu} / \mathrm{Zn}$ rich alloying element has the major contribution for the improvement in its performance but it adversely affects the corrosion performance in aggressive environment [2]. Various techniques have been developed to improve the corrosion resistance property of this alloy. Anodization (or) oxide layer formation is a conventional electrolytic conversion method to improve the corrosion and abrasion resistance of this alloy $[3,4]$. In general, sulphuric, oxalic, phosphoric or mixed acid electrolytes are used to produce nano to micron size porous oxide layers $[\mathbf{5}, \mathbf{6}]$. The developed porous oxide layers seldom provide sufficient corrosion resistance specifically in marine environment and results in catastrophic failure of the aircraft structures. Various processes are developed to seal this porous oxide layer in order to improve its corrosion resistance. Incorporation of metal oxyanions into a formed oxide layer by either in-situ process during anodization or as a post treatment enhances the corrosion resistance $[7,8]$.

Incorporation of hexavalent chromium ions into the oxide layer by chromic acid anodization process is the conventional method for aircraft structure due to its unique corrosion resistance property. However, the usage of $\mathrm{Cr}$ (VI) is restricted because of its toxicity [9]. Hence, the development of a process alternate to chromate is the current interest. Some of the developed chromate alternative sealers such as nickel acetate, cobalt acetate etc., for anodic oxide layer and their advantages/ disadvantages have been addressed [10]. Tayler et al. explained the different anodic and cathodic corrosion inhibitors such as vanadate, molybdate, tungstate, Cerate, Lanthanate, etc., as a suitable substitute for chromates [11]. Hamdy et al. reported that the vanadium oxy anion is a potential self-healing agent for bare AA2024 [12]. Potassium permanganate can also acts as a potential corrosion inhibitor for aluminum alloys [13, 14]. Corrosion performance of these oxyanions is not comparable with the hexavalent $\mathrm{Cr}$ ions. It appears that the presence of more than one oxyanion is needed to give long term corrosion protection. Since V and Mn acts as cathodic and mixed type of inhibitors respectively for AA 2024 , it is worthwhile to study the synergetic effect of incorporation of these oxyanions as a post treatment for anodized oxide layer.

In the present investigation the anodized oxide layer was formed on AA 2024 by sulphuric acid anodization process. The formed oxide layer was incorporated with $\mathrm{Mn}$ and $\mathrm{V}$ oxyanions during sealing process. For comparison, oxide layer was also incorporated only with Mn oxyanion. The coating formation and corrosion inhibition mechanisms were explained based on different characterization techniques such as field emission scanning electron microscopy (FESEM), energy dispersive X-ray analysis (EDAX), Raman spectroscopy, X-ray photoelectron spectroscopy (XPS), atomic force microscopy (AFM), electrochemical impedance spectroscopy (EIS) and potentiodynamic polarization. The salt spray test was also performed as an industrial practice. 


\subsection{Experimental}

\subsection{Specimen preparation}

As received unclad AA 2024 alloy specimens of size $25 \mathrm{~mm} \mathrm{X} 15 \mathrm{~mm} \mathrm{X} 1.2 \mathrm{~mm}$ were used as substrate materials for the present investigation. The specimens were ground with 800 and1200 SiC grit emery sheet, polished with $0.3 \mu \mathrm{m}$ alumina, rinsed with distilled water followed by ultrasonicated in acetone. The pretreatment steps used before oxide layer formation are as follows: (i) alkaline cleaning in phosphate, carbonate solution (ii) $\mathrm{NaOH}$ etching followed by (iii) deoxidizing in nitric acid. After each step, specimens were thoroughly rinsed with distilled water. Oxide layer was formed by using the specimen as anode and pure aluminum as cathode in sulphuric acid (10 V/V \%) electrolyte by applying constant current density (20 $\left.\mathrm{mA} \cdot \mathrm{cm}^{-2}\right)$ at room temperature. Conversion baths were used to incorporate oxyanions which contain only permanganate $(0.61 \mathrm{M})$ with additives $(\mathrm{MnO})$, permanganate and vanadate $(0.041 \mathrm{M})$ $(\mathrm{MnVO})$. The oxide layered specimens were immersed into the conversion baths for about 30 min at $78 \pm 2^{\circ} \mathrm{C}$. After the coating the samples were dried in air and kept in ambient condition for about $48 \mathrm{~h}$ and then taken for the characterization.

\subsection{Electrochemical measurements}

Electrochemical studies on the developed coatings were conducted using CHI604D Electrochemical Workstation. The test was carried out in non-de aerated $3.5 \mathrm{wt} \%(0.6 \mathrm{M}) \mathrm{NaCl}$ solution $(200 \pm 2 \mathrm{ml})$ using conventional three electrode cell equipped with coupon as working electrode $\left(1 \mathrm{~cm}^{2}\right)$, platinum foil and saturated calomel electrode (SCE) used as counter and reference electrodes respectively. The reference electrode was connected to a Luggin capillary and the tip of the Luggin capillary was kept closer to the surface of the working electrode to minimize IR drop. The coupon was kept in $\mathrm{NaCl}$ solution for an hour in order to establish the open circuit potential $\left(\mathrm{E}_{\text {ocp }}\right)$. The EIS studies were carried out in the frequency range of $100 \mathrm{kHz}$ - $0.1 \mathrm{~Hz}$. The applied AC signal amplitude was $10 \mathrm{mV}$ peak- to- zero at equilibrium potential. The impedance data is displayed as Bode plots. The Bode plot is a plot of $|Z|$ vs. frequency and frequency vs. - phase angle $(\theta)$, where $|Z|$ is the absolute impedance. The acquired data were curve fitted and analyzed using Zsimpwin program. The potentiodynamic polarization measurements were carried out with upper and lower potential limits of $\pm 200 \mathrm{mV}$ with respect to the $E_{\text {ocp. }}$ The Tafel plot obtained is represented as potential vs. log i. The corrosion current density $\left(i_{\text {corr }}\right.$ ) values were obtained by the extrapolation of cathodic and anodic regions. In order to study the corrosion inhibition nature of the coating for long term protection some of the freshly prepared specimens were immersed into $3.5 \% \mathrm{NaCl}$ solution and EIS data were collected after every $24 \mathrm{~h}$ periodically. Few freshly prepared specimens were also immersed and polarized at different time intervals. At least three samples were repeated in each experiment to get the reproducible results. 


\subsection{Atomic force microscopy}

The information about the surface roughness was examined with the help of atomic force microscopy (AFM) (Model SSI, CSEM make). It equipped with silicon nitride cantilever $\left(\mathrm{Si}_{3} \mathrm{~N}_{4}\right.$ tip, gold reflective coating, V-shape, 200 or $100 \mathrm{~mm}$ long). With the tip in contact with the sample surface, short range repulsion forces were probed. The surface topography and the roughness were scanned by monitoring the cantilever deflection.

\subsection{Raman Analysis}

Raman spectroscopy experiments were carried out at room temperature in the spectral range 200-1200 $\mathrm{cm}^{-1}$ using DILOR-JOBIN-YVON-SPEX integrated Raman spectrometer (Model Labram). The spectrometer consists of a microscope coupled confocally to a $300 \mathrm{~mm}$ focal length spectrograph equipped with two switchable gratings (300 and 1800 grooves/ mm). A He-Ne $20 \mathrm{~mW}$ red colour laser beam was used as the excitation source. The laser was reflected by a notch filter towards the sample under a microscope and the Raman scattering was totally transmitted through the notch filter towards the confocal hole and entrance slit of the spectrometer. The spectrum was recorded in a Peltier cooled charge coupled device detector.

\subsection{X-ray photoelectron spectroscopy (XPS) study}

The XPS experiments were recorded with a Thermo Fisher Scientific Multilab 2000 spectrometer equipped with a non-monochromatic AlK $\alpha$. X- ray excitation source $(1486.6 \mathrm{eV})$ operated at $15 \mathrm{kV}$ and $10 \mathrm{~mA}$. The binding energies $\left(\mathrm{E}_{\mathrm{B}}\right)$ reported here were calculated with reference to $\mathrm{C} 1 \mathrm{~s}$ peak at $284.5 \mathrm{eV}$ with a precision of $\pm 0.1 \mathrm{eV}$. The residual pressure inside the analysis chamber was kept at $10^{-9}$ Torr for $5 \mathrm{~h}$ in order to desorb any volatile species present on the surface. After $5 \mathrm{~h}$, samples were transferred into the analyzer chamber with Ultrahigh vacuum (UHV) at $10^{-9}$ Torr housing the analyzer. The high resolution spectrum was curve fitted with Gaussian peaks after subtracting a linear background by PeakFit V 4.11 program. The fitted peak is represented in figures as red solid line and the measured data are in black dotted line. For Gaussian peaks, slightly different full width at half maximum (FWHM) was used for different chemical states. The Mn and Mo signal shapes were analyzed as a set of doublets separated by defined binding energy scale, intensity contribution, position and width.

\subsection{Continuous salt spray}

Salt spray test (Ascott Sxp120) was carried out as per ASTM B117. All the specimens were examined before and after the corrosion exposure of 2 weeks using field emission scanning electron microscopy (FESEM) attached with energy dispersive X-ray analysis (EDS) and also Nikon SLR camera. 


\subsection{Results and discussion}

3.1 Surface Morphology and composition analysis (EDAX) of the modified oxide layer

The plain oxide layer (PO-without modification) appears as creamy white in colour and it has already been discussed in our previous report [15]. Fig. 1 shows the photographic and scanning electron microscope images of as prepared $\mathrm{MnO}$ and $\mathrm{MnVO}$ specimens. The smooth, uniform and yellowish orange colour of $\mathrm{MnO}$ and $\mathrm{MnVO}$ from the photographic images (Fig. 1a and $b$ ) reveals that the anodized surface is effectively modified during the sealing process. The microscopic images (at lower magnification) of $\mathrm{MnO}$ and $\mathrm{MnVO}$ displays "petal-shaped" structure (Fig. 1c and d). Wafers et al. reported that the aluminum salt precipitation over the surface during the boiling water sealing process leads to this type of morphology and mentioned as "smudge" formation $[\mathbf{1 6}, \mathbf{1 7}]$. The higher magnification (Fig. 1e and f) clearly indicates the tortuous porous and cracked morphology of the developed coatings. Both specimens show a crack width of about 1-2 $\mu \mathrm{m}$ throughout the surface and the width is comparatively more on $\mathrm{MnO}$ than MnVO. However, the presence of nano thread like structure appearance on MnVO (Fig. 1h) clearly differentiates the incorporation/precipitation of different species from the different conversion baths used.

The composition obtained from energy dispersive X-ray analysis and their quantitative information is given in Table 1. From the table it is evident that the incorporation of Mn and Mn$\mathrm{V}$ oxyanions from their respective baths can be corroborated. It indicates that the concentration of $\mathrm{Mn}$ is (between 0.3 to 0.8 at. \%) considerably lower compared to $\mathrm{V}$ oxyanion (11 at. \%) on both $\mathrm{MnO}$ and $\mathrm{MnVO}$ specimens though the quantity of vanadate is lower in the conversion bath. It also shows a slightly increased inclusion of $\mathrm{Mn}$ in the presence of vanadium oxyanion.

Based on the surface morphology and composition analysis it can be stated that the rate of incorporation of vanadium is higher compared to Mn oxyanion in the given condition (this may be the characteristics of the oxyanion and the sealing bath condition). In general during the sealing process the conversion of alumina into hydrated alumina followed by re-crystallization of boehmite $(\mathrm{AlOOH})$ is the predicted sealing reaction mechanism when the bath condition is above $50^{\circ} \mathrm{C}$. In the present investigation since the sealing bath temperature is kept about $80^{\circ} \mathrm{C}$, the converted boehmite may simultaneously involve in the conversion reaction with the incoming metal oxyanions and consequently an irreversibly adsorbed conversion layer forms on the surface. This conversion layer coverage on anodized layer may be significantly higher in the case of $\mathrm{MnVO}$ due to the higher incorporation of $\mathrm{V}$ oxyanion which results in the crack width reduction. The thread like appearance on MnVO may be due to the precipitation of vanadium based compound on the surface of anodized alumina layer. From our previous study [14] we have observed that the Mn oxyanion preferentially involve in the direct redox reaction with the substrate (AA2024) due to the galvanic couple formation between Al (anodic) and $\mathrm{Cu}$ (cathodic). In the present study since there is no significant amount of $\mathrm{Cu}$ present in the developed oxide layer (Table 1) the galvanic couple formation is negligible and hence the rate of incorporation of $\mathrm{Mn}$ is limited by direct interaction with $\mathrm{Al}^{3+}$ (boehmite). 
Atomic force microscopy has been employed to study the three dimensional topography and surface roughness of the $\mathrm{MnO}$ and MnVO specimens. The AFM images of the as prepared specimens are shown in Fig. 1 and the roughness values are given in Table 2. From both the figure and the table it is evident that the MnO surface is coarse compared to MnVO specimen. However, the sealing considerably reduces the overall surface roughness. The surface 3D image of $\mathrm{MnO}$ exhibits with the collection of mountains and valleys and randomly distributed needle shaped structures. From the Fig. 2a, the presence of sharp protrusions on $\mathrm{MnO}$ with a peak height of about $1 \mu \mathrm{m}$ and width of about 3 to $7 \mu \mathrm{m}$ can be seen. The surface of MnVO (Fig. 2b) is more homogeneous and smooth compared to MnO surface. Nevertheless, the peak height (about $600 \mathrm{~nm}$ ) and width (about 2 to $3 \mu \mathrm{m}$ ) are lower compared to $\mathrm{MnO}$ specimen.

AFM results suggest that the anodic oxidation process generates random roughness due to the non-uniform oxidation of matrix (aluminum) and intermetallic particles. In general, a small reduction in the roughness after sealing can be attributed to the amorphous boehmite gel formation on pore walls and mouth and also the extent of plugging of pores. This explanation will be suitably fit for the $\mathrm{MnO}$ specimen since the Mn oxyanion incorporation into the oxide layer is very less and it does not alter the surface microstructure and roughness to a greater extent. On the other hand about 4 times reduced roughness of MnVO compared to plain oxide layer indicates the effective surface modification by vanadium oxyanions. This roughness reduction can be attributed mainly to the precipitation of vanadium rich aluminum oxides over the surface. Hamdy et al. reported that the vanadium conversion coating develops a more compact, smooth and uniform structure over the bare aluminum alloy specimen [19].

\subsection{Micro Raman analysis}

Fig. 3a shows the Raman spectra of the as prepared $\mathrm{MnO}$ and $\mathrm{MnVO}$ specimens. From the figure, a broad signal from 550 to $700 \mathrm{~cm}^{-1}$ is common for both $\mathrm{MnO}$ and $\mathrm{MnVO}$ which can be attributed to the presence of different Mn oxides and mixed Al-Mn oxides [20, 21]. Especially the peak between 630 and $645 \mathrm{~cm}^{-1}$ depicts the formation of $\gamma-\mathrm{Mn}_{2} \mathrm{O}_{3}$ induced by the presence of $\mathrm{Al}_{2} \mathrm{O}_{3}$ [21]. In general, the expected two major manganese oxides in the alumina layer are $\mathrm{Mn}_{2} \mathrm{O}_{3}$ and $\mathrm{Mn}_{3} \mathrm{O}_{4}$ [14]. In the case of $\mathrm{MnVO}$, three significant sharp and intense peaks are observed at 944,359 and $210 \mathrm{~cm}^{-1}$. The intense and broad signal from 800 to $1000 \mathrm{~cm}^{-1}$ can be attributed to the presence of polyvanadate in the oxide layer [22, 23]. The peak seen at $992 \mathrm{~cm}^{-1}$ corresponds to the terminal oxygen $(\mathrm{V}=\mathrm{O})$ stretching vibration mode which results from an unshared oxygen. The Raman signal at $694 \mathrm{~cm}^{-1}$ can be assigned to the doubly coordinated oxygen $\left(\mathrm{V}_{2}-\mathrm{O}\right)$ stretching mode which results from corner shared oxygen in common to two pyramids (minor peak) [24]. A small hump at $750 \mathrm{~cm}^{-1}$ shows the presence of mixed aluminum Mn oxide which is clearly visible in MnVO. 
Therefore the presence of mixed metal oxide compounds in both $\mathrm{MnO}$ and $\mathrm{MnVO}$ specimens confirms that the $\mathrm{Mn}$ and $\mathrm{V}$ oxyanions are irreversibly adsorbed over the anodized alumina layer. The vanadate incorporation inside the PO is in the form of polymeric species. In general, $\mathrm{V}$ will be mainly present in the form of tetrahedrally coordinated metavanadate in neutral to near basic solutions. Ralston et.al, reported that the presence of major vanadium species such as $\mathrm{V}_{4} \mathrm{O}_{12}{ }^{4-}, \mathrm{V}_{3} \mathrm{O}_{9}{ }^{3-}, \mathrm{VO}_{3}(\mathrm{OH})^{2-}$ and $\mathrm{V}_{2} \mathrm{O}_{6}(\mathrm{OH})^{3-}$ in the basic $\mathrm{pH}$ (between 8 and 9) solution [25]. In the present investigation, the bath $\mathrm{pH}$ and concentration of vanadate is about analogous. The presence of both $\mathrm{V}=\mathrm{O}$ and $-\mathrm{V}-\mathrm{O}-\mathrm{V}$ - from Raman study confirms the polymeric form of vanadate. It is also predicted that due to the interaction between $\mathrm{Mn}$ and $\mathrm{V}$ oxyanions there may be possibility for the formation of inter metal oxide species ( $\mathrm{Mn}-\mathrm{V}$ compounds) during incorporation. Briand et al. [26] reported that $\mathrm{Mn}_{3}\left(\mathrm{VO}_{4}\right)_{2}$ can be identified from a sharp Raman signal at 842 and $654 \mathrm{~cm}^{-1}$. In the present investigation also the spectrum contains the signals (for a wide range) in the similar regions. This type of mixed oxide formation may also results in higher amount of $\mathrm{Mn}$ incorporation during the vanadate inclusion in the case of $\mathrm{MnVO}$ (which is observed from EDAX results). It requires further investigation to confirm this prediction. The reaction mechanism of $\mathrm{Mn}$ and $\mathrm{V}$ with anodized alumina during sealing process will be discussed in detail later.

\subsection{XPS analysis}

The evidence for the different oxidation states of various elements can be obtained by Xray photoelectron spectroscopy (XPS). However, XPS has the limitation to clearly discriminate the different oxides/hydroxides of the same element in identical oxidation state. The quantitative results obtained from XPS analysis of $\mathrm{MnO}$ and $\mathrm{MnVO}$ are given in the Table 3. From the table it is evident that the presence of $\mathrm{Mn}$ (common species) in the case of both $\mathrm{MnO}$ and $\mathrm{MnVO}$ along with $\mathrm{Al}$ and $\mathrm{O}$ elements. In addition, the presence of sulphur at the surface may be due to the adsorbed species during the anodization process in sulphuric acid bath. The surface and subsurface composition plays an important role in the corrosion and its prevention reaction. From the Table 3, it is also evident that the subsurface layer composed of $\mathrm{Mn}$ rich oxides/hydroxides compared to the surface layer on both $\mathrm{MnO}$ and MnVO. On the other hand, $\mathrm{MnVO}$ composed of the surface oxide layer rich in vanadium. It indicates that the reaction of vanadate with the surface of alumina layer (hydroxide rich layer) is mainly based on the adsorption of vanadium species followed by hydrolysis (a superficial phenomenon). The very low $\mathrm{Al}$ and high $\mathrm{O}$ content in the case of $\mathrm{MnVO}$ indicates that the vanadium rich oxide layer effectively covers the alumina surface.

Fig. 3a and $\mathrm{b}$ display the high resolution XP spectra of different species before and after corrosion reaction respectively. The $\mathrm{Mn}$ peak obtained from $\mathrm{MnO}$ and $\mathrm{MnVO}$ shows the presence of $+2,+4$ and +7 states of $\mathrm{Mn}$ ions such as $\mathrm{MnO}, \mathrm{MnO}_{2}$ and $\mathrm{MnO}_{7}{ }^{-}$respectively which is similar to our previous report [14]. In general, vanadium can exist in two different oxidation states such as +5 and +4 . In the present study, $\mathrm{V} 2 \mathrm{p}_{3 / 2}$ shows a broad peak between 520 and $514 \mathrm{eV}$ indicates the presence of multivalent state of $\mathrm{V}$. The de-convulsion of $\mathrm{O} 1 \mathrm{~s}$ spectrum 
indicates the presence of mixed oxides, hydroxides and hydrated oxides of different species in both $\mathrm{MnO}$ and $\mathrm{MnVO}$ specimens.

\subsection{Coating formation mechanism}

Based on the above studies the major plausible reactions of $\mathrm{Mn}$ and $\mathrm{V}$ oxyanions with the developed anodized oxide layer during sealing process is explained below.

$$
\mathrm{Al}_{2} \mathrm{O}_{3}+\mathrm{H}_{2} \mathrm{O} \rightarrow 2 \mathrm{AlO}(\mathrm{OH})
$$

Reaction (1) is widely accepted for alumina to form boehmite crystals during the sealing process in boiling water.

In the present investigation since the sealing bath is kept slightly in basic condition the following reaction (2) will be the predominant and therefore the surface will be enriched with the hydroxyl ions.

$$
\mathrm{Al}_{2} \mathrm{O}_{3}+2 \mathrm{OH}^{-}+3 \mathrm{H}_{2} \mathrm{O} \rightarrow \mathrm{Al}(\mathrm{OH})_{4}^{-}
$$

In the case of $\mathrm{Mn}$, the $\mathrm{MnO}_{2}$ is predominantly found on both the specimens and this may be due to the following reaction (3).

$$
\mathrm{MnO}_{4}^{-}+3 \mathrm{H}_{2} \mathrm{O}+3 \mathrm{e}^{-} \rightarrow \mathrm{MnO}_{2}+4 \mathrm{OH}^{-}
$$

Since XPS analysis revealed the presence of a surface film rich in vanadium and also the multivalent (presence of both +4 and +5 ) state in the tetrahedral form the possible formation of bonding with anodized specimen is shown in Fig. 5.

\subsection{Potentiodynamic Polarization}

Fig. 6 shows the potentiodynamic polarization plots obtained for $\mathrm{MnO}$ and $\mathrm{MnVO}$ after 1,168 and $336 \mathrm{~h}$ of immersion in $3.5 \% \mathrm{NaCl}$ solution. The negative shift in corrosion potential $\left(\mathrm{E}_{\text {corr }}\right)$ and reduced steady state cathodic current after $1 \mathrm{~h}$ immersion for MnVO compared to $\mathrm{MnO}$ indicates the reduced rate of oxygen reduction reaction. This behavior is consistent irrespective of the immersion time for MnVO specimen. The anodic curve of the Tafel plot comprises of complex reactions such as oxidation, attack of $\mathrm{Cl}^{-}$ion, desorption/dissolution of the incorporated species, etc. The $\mathrm{MnO}$ shows shallow current peaks (mentioned as (a) and (b) in the figure) followed by a random oxidation reaction in the anodic branch. This indicates the random attack of $\mathrm{Cl}^{-}$ions due to the incomplete sealing of the pores by only Mn oxyanions. In the case of $\mathrm{MnVO}$ the oxidation reaction is uniform and the rate of oxidation is higher compared to $\mathrm{MnO}$ after $1 \mathrm{~h}$. From the graph it can also be observed that the significant changes in the anodic reaction kinetics with respect to immersion time for both $\mathrm{MnO}$ and $\mathrm{MnVO}$.

The corrosion parameters obtained from potentiodynamic polarization plots obtained for $\mathrm{MnO}$ and $\mathrm{MnVO}$ after different immersion times are listed in Table 4. From the table it is evident that the similar corrosion current density ( $\mathrm{i}_{\text {corr }}$ ) value of $\mathrm{MnO}$ and $\mathrm{MnVO}$ indicates the 
corrosion behaviour of both the specimens is comparable after $1 \mathrm{~h}$ immersion. No significant change in the $\mathrm{i}_{\text {corr }}$ value of both the specimens after $168 \mathrm{~h}$ indicates that the effective inhibition of $\mathrm{Cl}^{-}$ion attack during immersion period. Only $\mathrm{E}_{\text {corr }}$ value shift towards negative region after $168 \mathrm{~h}$ immersion may be due to the cathodic protection behavior of the sealed coating. After $336 \mathrm{~h}$ of immersion, the $i_{\text {corr }}$ value increases about one order of magnitude for both the specimens reveal the increased corrosion reaction.

The XP spectra results (Fig. 4b) after $336 \mathrm{~h}$ polarized specimens showed that the formation of more hydroxyl species due to the corrosion process compared to the as prepared specimens. The Raman spectrum results after corrosion test also showed significant shift in the peak position compared to the as prepared specimens. The Raman signal (Fig. 3b) for Mn became fully noisy after $336 \mathrm{~h}$ polarized specimens for both $\mathrm{MnO}$ and $\mathrm{MnVO}$ compared to as prepared specimen indicate that the quantity of Mn oxyanion is negligible on both the specimens. It also revealed that the Raman signals observed from MnVO specimen were mainly corresponding to the $\mathrm{V}$ oxyanion species. The EDAX analysis results after $336 \mathrm{~h}$ polarization (Table 5) also corroborates the similar behavior of MnO and MnVO obtained from XPS and Raman analysis. From the table it is evident that the reduced quantity of both V (about 11times) and $\mathrm{Mn}$ indicates the effective participation of these ions against corrosion reaction during immersion in $\mathrm{NaCl}$ solution.

In general, the enhanced corrosion inhibition behavior of the sealed anodic oxide layer may be due to the plugging of pores (or) ions present inside the pores (or) both. The Raman and XPS results clearly indicate that the attack of $\mathrm{Cl}^{-}$ions during immersion of $\mathrm{MnO}$ and $\mathrm{MnVO}$ in $\mathrm{NaCl}$ solution enhances the localized $\mathrm{pH}$ leads to the formation of more hydroxide ions. This reaction initiates the hydrolysis of polymeric vanadium species to form highly soluble $\mathrm{V}$ hydroxides. Similarly, the conversion of Mn oxides into soluble hydroxides is expected. The formation of soluble chlorides/oxychlorides of $\mathrm{Mn}$ and $\mathrm{V}$ during the corrosion process is also possible. The re-adsorption of these species over the surface during the corrosion reaction also plays an important role to inhibit the further attack of $\mathrm{Cl}^{-}$ion. In the present investigation, the observed microstructure and composition analysis before and after corrosion by various techniques reveals that the corrosion reaction is mainly dependent on the plugging of pores, compactness of the coating, solubility of the deposited oxyanions, its chemical reaction with the $\mathrm{Cl}^{-}$ion, the formation of corrosion products and its inhibition effect for further protection, etc.

\subsection{Electrochemical Impedance Spectroscopy}

Electrochemical impedance spectroscopy (Bode plots) obtained for $\mathrm{MnO}$ and $\mathrm{MnVO}$ at different immersion times in $3.5 \% \mathrm{NaCl}$ solution are given in Fig. 7. From the spectra it appears that the structural arrangement of the oxide layers on $\mathrm{MnO}$ and $\mathrm{MnVO}$ are different from each other. After $1 \mathrm{~h}$ immersion, phase angle curve of $\mathrm{MnO}$ clearly shows a two time relaxation process. The small signal at higher frequency between 10 and $100 \mathrm{kHz}$ is the indication of the partially sealed porous oxide layer and a broad phase angle curve from medium to lower 
frequency with nearly $90^{\circ}$ shows the capacitive behavior of the barrier layer. On the other hand, the appearance of a shallow peak at $40 \mathrm{~Hz}$ of MnVO differentiates the sealed porous oxide layer from the barrier layer and this can be attributed to the poor incorporation/loosely adsorbed vanadium oxyanions into the pores and cracks [27]. A small hump between 500 and $1000 \mathrm{~Hz}$ indicates that the sealed oxide layer is composed of multi layer structure. The evolution of the EIS spectra with respect to immersion time in $\mathrm{NaCl}$ solution of $\mathrm{MnO}$ indicates that the capacitive behavior of the barrier layer becomes resistive after $48 \mathrm{~h}$ of immersion. The plateau in the low frequency phase angle curve indicates the degradation of the barrier layer due to the $\mathrm{Cl}^{-}$ion attack [28]. The phase angle maxima shifts from intermediate frequency to lower frequency region with respect to immersion time shows the diffusion of the electrolyte through the available pores and cracks towards the substrate. At higher frequency region the new plateau formation in phase angle curve and the increased $|\mathrm{Z}|$ value with respect to immersion time may be due to the formation of a new layer (corrosion product) or self-sealing of the pores. In the case of MnVO, a small displacement of the shallow peak towards higher frequency region during immersion period indicates the attack of $\mathrm{Cl}^{-}$ion.

However, the obtained data were fitted with suitable equivalent circuits in order to obtain reliable information about the quality of the sealing and stability of the oxide layer with respect to immersion time and are shown in Fig. $8 \mathrm{a}$ and b. In this circuit the constant phase element (CPE) is used in order to explain the deviation from the ideal capacitive behaviour. The impedance of the $\mathrm{CPE}$ is $\mathrm{Z}_{\mathrm{CPE}}=1 / \mathrm{Q}(\mathrm{j} \omega)^{\mathrm{n}}$, where ' $\mathrm{Q}$ ' is the pseudo capacitance, ' $\mathrm{j}$ ' is the imaginary function $(\sqrt{ }-1)$, ' $\omega$ ' is the angular frequency and ' $n$ ' corresponds to the deviation from the ideal behaviour of a pure capacitor. In this case, Rs represents the solution resistance, R1 and Q1 represents the resistive and capacitive responses of the sealed oxide layer and R2 and Q2 are attributed to the barrier oxide layer for $\mathrm{MnO}$ specimen. In the case of MnVO, R1 and Q1, R2 and Q2 and R3 and Q3 are the resistive and capacitive responses of the surface, intermediate and the barrier layers respectively. The fitted values are given in Table 6. From the table it is evident that the lower $\mathrm{n} 1$ value of $\mathrm{MnO}$ compared to $\mathrm{MnVO}$ indicates highly rough surface (heterogeneous) of $\mathrm{MnO}$. This corroborates the results obtained from the AFM study. The gradual decrease in R1 value of $\mathrm{MnO}$ indicates the initiation of corrosion attack of the sealed porous oxide layer up to $48 \mathrm{~h}$. But the increased value of R1 for further immersion time shows that the corrosion attack of the $\mathrm{MnO}$ sealed porous layer is a complex process. Similarly the gradual decrease in the R2 indicates the degradation of barrier layer by $\mathrm{Cl}^{-}$ion attack during immersion in $\mathrm{NaCl}$ solution. After $336 \mathrm{~h}$ the data is well fitted with the three time constants circuit and is shown in Fig. 8b. Garcia et.al reported that the new time constant introduction after long term immersion can be attributed to the self-sealing behaviour of the anodized specimen [5]. Therefore, in the present study, the three time constant after $336 \mathrm{~h}$ immersion can be attributed to the formation of the corrosion products as an intermediate layer. The very low resistance (R2) value obtained from this intermediate layer indicates the resistive behavior of this layer and is insignificant. In other words, the conductivity of this layer is higher compared to the sealed porous and barrier oxide 
layer. Therefore, It is believed that the formation of a compact (n2 value is about 0.9) and thin hydrated oxide/hydroxide rich layer due to the corrosion.

In the case of MnVO (Table 7) the R1 value decreases gradually during immersion time and this value is always higher compared to the $\mathrm{MnO}$ at all the immersion times. This indicates the rate of degradation of the sealed porous oxide layer of $\mathrm{MnVO}$ is slow compared to $\mathrm{MnO}$. The decrease in R2 value from 1 to $24 \mathrm{~h}$ immersion indicates the attack of the intermediate layer by $\mathrm{Cl}^{-}$ions. But during further immersion time the increase in $\mathrm{R} 2$ value indicates the additional protection offered by this layer up to $144 \mathrm{~h}$. This increase in protection behavior can be attributed to the formation of a passive film which provides additional protection for the further attack of $\mathrm{Cl}^{-}$ions. The $\mathrm{R} 3$ value is reduced to half after $24 \mathrm{~h}$ immersion and a sudden drop about 15 times after $48 \mathrm{~h}$ indicates that the initial attack of the barrier layer is slow and it becomes severe during immersion period. However, the resistance behavior of the barrier layer is also higher at all the immersion times compared to $\mathrm{MnO}$.

\subsubsection{Damage function of the coating}

The damage function (D-factor) is a useful measure for the analysis of corrosion susceptibility and prediction of a coating for the practical application [29]. In general, this factor is known to evaluate the barrier oxide layer susceptibility for long term corrosion protection (comparison between $1 \mathrm{~h}$ and $168 \mathrm{~h}$ ) in aggressive environment. The $\mathrm{D}$ value tends to zero (lower value) represents perfect corrosion protection behavior and tends to one (towards higher value) indicates the poor corrosion performance. In the present investigation, we have tried to utilize this factor in order to explain the active corrosion protection performance of the oxyanions. Table 8 shows the measured modulus of impedance values at $0.1 \mathrm{~Hz}$ for both $\mathrm{MnO}$ and $\mathrm{MnVO}$ with respect to different times and the calculated D-factor values. The calculated negative value of the D-factor can be attributed to the self-healing ability of the oxyanions/passive layer formation over the barrier layer for further attack of $\mathrm{Cl}^{-}$ion. The Damage function (D) is calculated using the following equation [29]:

$\mathrm{D}=\log \left(\mathrm{Z}_{1} / \mathrm{Z}_{\mathrm{t}}\right)_{0.1 \mathrm{~Hz}}$

where, $Z_{1}$ and $Z_{t}$ are the modulus of impedance after $1 \mathrm{~h}$ and a known immersion time (t) obtained at $0.1 \mathrm{~Hz}$.

From the table it is evident that the increase in $\mathrm{D}$ value of $\mathrm{MnO}$ between 24 and $48 \mathrm{~h}$ compared to 1 and $24 \mathrm{~h}$ indicates the severe attack of the barrier layer by aggressive $\mathrm{Cl}^{-}$ion. During further immersion, a gradual decrease in this value indicates that the corrosion products saturates the pores and cracks which slows down the further attack of the barrier layer by $\mathrm{Cl}^{-}$ ions. The negative shift in this value after $336 \mathrm{~h}$ confirms the formation of a passive layer which gives additional protection to the barrier layer. About 10 times lower value (towards zero) of MnVO compared to $\mathrm{MnO}$ between 1 and $24 \mathrm{~h}$ indicates that the barrier layer attack is not significant in the case of MnVO. The increased value after further immersion (between 24 and 
$48 \mathrm{~h}$ ) indicates the pronounced attack of the barrier layer (or) leaching of soluble ions from the barrier layer similar to the $\mathrm{MnO}$ specimen. The negative value between 48 and $96 \mathrm{~h}$ indicates the passive layer formation. Since vanadates are known for active corrosion protection, this quick passivation process (compared to the $\mathrm{MnO}$ ) can be attributed to the self-healing behavior of the vanadium oxyanion. For further immersion times, the increase followed by decrease and again reaching the negative value after $336 \mathrm{~h}$ confirms the self-healing ability of the vanadium oxyanion. The only vanadate without Mn oxyanion incorporated oxide layer also showed similar corrosion behaviour of $\mathrm{MnVO}$ (is not shown).

In general, the corrosion attack on a developed oxide layer can be explained as follows: corrosive species adsorption (in this case $\mathrm{Cl}^{-}$ion) on the surface, chemical reaction with the oxide layer and simultaneous diffusion of the electrolyte (ion/mass transfer) towards the inner layer and followed by the diffusion of the corrosion products (mass transfer). The rate of adsorption, attack and diffusion of the electrolyte significantly decides the rate of corrosion reaction. Based on the electrochemical studies we have understood that the $\mathrm{V}$ oxyanion protection is significantly higher compared to the Mn oxyanion for the anodized oxide layer. The slow $\mathrm{Cl}^{-}$ion attack on MnVO surface can be attributed to the effective inhibition of the incorporated vanadate oxyanion (negative ion) against $\mathrm{Cl}^{-}$ion attack. But this vanadate ion could not completely prevent the attack of $\mathrm{Cl}^{-}$ion since most of the deposited products (oxides, hydroxides, chlorides and oxy chlorides) are soluble in nature and also the specimen is continuously in contact with $\mathrm{NaCl}$ solution. When this corrosive ion reaches the aluminum rich oxide layer, the rate of attack becomes severe. Based on the spectroscopic studies before and after corrosion, it can be stated that tetrahedral vanadate species incorporation into the oxide layer and its reduction (to lower oxidation state) followed by re-adsorption on the defective sites could be the main reason for the enhanced protection of $\mathrm{MnVO}$ compared to $\mathrm{MnO}$ specimen. The active corrosion protection offered by vanadate can be due to the increase in localized $\mathrm{pH}$ which results in precipitation of hydroxyl species of vanadium (This is corroborated by XPS results).

\subsection{Salt spray exposure}

Fig. 9 shows the digital and FESEM images of $\mathrm{MnO}$ and MnVO specimens after $168 \mathrm{~h}$ of salt spray exposure. From the photographic images no significant corrosion products can be visualized on both the specimens after $168 \mathrm{~h}$ of exposure. The lower (Fig. 9c and d) and higher (Fig. 9e and f) magnification FESEM images show significant difference in the morphology after corrosion compared to the as prepared specimen (Fig. 1c-h). The surface of $\mathrm{MnO}$ appears as

rough and with several voids and cracks whereas; MnVO shows smooth and minute cracks. The composition analysis on $\mathrm{MnO}$ shows the presence of different elements (in at. \%) such as $\mathrm{O}, \mathrm{Al}$ and $\mathrm{Mn}$ about 71.8, 26.1 and 0.1 respectively. In the case of MnVO: $\mathrm{O}, \mathrm{Al}$ and $\mathrm{V}$ is about 66.6, 24.4 and 7.4 respectively. While comparing this vanadate concentration of $\mathrm{MnVO}$ with the as prepared (Table 1) and after $336 \mathrm{~h}$ polarized specimens (Table 5) it can be observed that a steady 
decrease in V quantity with respect to the exposure time. In order to find out the long term corrosion protection behaviour of the coating few freshly prepared specimens were exposed up to $2000 \mathrm{~h}$ of neutral salt spray and their photographic images are shown in Fig. 10. From the figure, the development of pits and stains (Fig. 10a and b) on the surface of $\mathrm{MnO}$ can be visually observed. Whereas, only discolouration of the coating is observed on the MnVO surface and also no significant corrosion product or stains can be seen even in the mechanically damaged area after $2000 \mathrm{~h}$ of salt fog exposure (Fig. 10c and d).

\subsection{Conclusions}

The plain oxide layer was developed on AA2024 by sulphuric acid anodization process and followed by $\mathrm{Mn}$ and $\mathrm{Mn}-\mathrm{V}$ oxyanions were successfully incorporated during sealing process as a post treatment. The results obtained from EDAX, Raman and XPS spectroscopy revealed that the concentration of vanadium oxyanion was higher compared to $\mathrm{Mn}$ and also both the ions were present in multivalent oxidation states. It also revealed that the vanadate exists in the form of polymeric species (metavanadate) on the anodized oxide layer. The potentiodynamic polarization study with respect to different immersion times in $3.5 \% \mathrm{NaCl}$ solution revealed that the localized attack of $\mathrm{Cl}^{-}$was prevented by vanadate species even after $336 \mathrm{~h}$ of immersion. The EIS immersion study revealed that though the barrier layer resistance (R3) is significantly reduced after $48 \mathrm{~h}$ of immersion, the active corrosion protection provided by vanadium oxides could be the main reason for the prolonged corrosion resistance of MnVO. The Raman and XPS analysis after corrosion test revealed that the improved corrosion inhibition of $\mathrm{MnVO}$ was mainly due to the presence of polyvanadate species in the sealed oxide layer. Neutral salt spray test results revealed that no significant corrosion products were found on MnVO surface even after $2000 \mathrm{~h}$ of exposure.

\section{Acknowledgements}

The authors are thankful to Mr. Shyam Chetty, Director, CSIR NAL and Head, SED for their constant support and encouragement to carry out this work. We thank Dr. C. Anandan, Mr. Siju and Mr. Praveen for XPS, FESEM and AFM studies. We thank Mr. Ganesh and Mr. Pradeep premkumar for their help while conducting experiments. We acknowledge the financial assistance received from CSIR Supra Project under $11^{\text {th }}$ Five year plan scheme for carrying out this work.

\section{References}

[1] J. Jones, Plat. Surf. Finish. 75 (1990) 20.

[2] S. Wernick, R. pinner, The Surface Treatment and Finishing of Aluminum and its Alloys, Drapper 1959.

[3] H. Wang, H.Yi and H.Wang, Appl.Surf. Sci. 252 (2005) 1662.

[4] Julien Escobar, Laurent Aruralt, Viviane Turq, Appl. Surf. Sci. 258 (2012) 8199. 
[5] M. Garcia-Rubio, M.P. de Lara, P. Ocon, S. Diekhoff, M. Beneke, A. Lavia, I. Garcia, Electrochim. Acta 54 (2009) 4789.

[6] J.P. Dasquet, D. Caillard, E. Conforto, J.P. Bonino, R. Bes, Thin Solid Films 371 (2000) 190

[7] V. Moutarlier, M.P. Gigandet, B.Normand, J. Pagetti, Corros. Sci. 47 (2005) 937.

[8] Xingwen Yu and Chunan Cao, Thin Solid Films 423 (2003) 252.

[9] S. Morisaki, Y. Ogawa, T. Maeno, C. Yonezewa, H. Ito, H. Sawahata, J. Surf. Fin. Soc. of Japan. 47 (1996) 456

[10] R. Mason, M. Klingenberg, S. Clark, M. Miller, E.Berman, N. Voevodin, Metal Finish. 109 (2012) 275.

[11] S.R. Tayler, B.D. Chambers US patent 0000958 (2009).

[12] A.S. Hamdy, I. Doench, H. Mohwald, Thin Solid Films 520 (2011) 1668.

[13] Viswanathan S. Saji, Recent Patents on Corros. Sci. 2 (2010) 6.

[14] G. Yoganandan, J.N. Balaraju, V.K. William Grips, Appl. Surf. Sci. 258 (2012) 8880.

[15] J.N. Balaraju, A. Srinivasan, G. Yoganandan, V.K. William Grips, K.S. Rajam, Corros. Sci. 53 (2011) 4084.

[16] K. Wefers, Aluminium 49 (1973) 553

[17] K. Wefers, Aluminium 49 (1973) 622

[18] Chan Lee, Hyungmo Kim, Ho Seon Ahn, Moo Hwan Kim, Joonwon Kim, Appl. Surf. Sci. 258 (2012) 8431.

[19] Abdel Salam Hamdy, I. Doench, H. Mohwald, Thin Solid Films 520 (2011) 1668.

[20] Florina Buciuman, Florin Patcas, Radu Craciun, Dietrich RT Zahn, Phys. Chem. Chem. Phy. 1 (1999) 185.

[21] C.M. Julien, M. Massot, C. Poinsignon, Spectrochim. Acta 60 (2004) 689.

[22] B.M. Weckhuysen, D.E. Keller, Catalysis Today 78 (2003) 25.

[23] B.L. Hurley, S. Qiu, R.G. Buchheit, J. Electrochem. Soc. 158 (2011) C125.

[24] Se-Hee Lee, Hyeonsik M. Cheong, Maeng Je Seong, Ping Liu, C. Edwin Tracy, Angelo Mascarenhas, J. Roland Pitts, Satyen K. Deb, Solid State Ionics 165 (2003) 111 . [25] K.D. Ralston, S. Chrisanti, T.L. Young, R.G. Buchheit, J. Electrochem. Soc. 155 (2008) C350. 
[26] Laura E. Briand, Jih-Mirn Jehng, Laura Cornaglia, Andrew M. Hirt, Israel E. Wachs, Catalysis Today 78 (2003) 257.

[27] F. Mansfeld, M.W. Kendig, J. Electrochem. Soc 100 (1988) 828.

[28] Fanny snogan, Christine Blanc, Georges Mankowski, Nadine pebere, Surf. Coat. Technol. 154 (2002) 94.

[29] Domingues, J.C.S. Fernandes, M. Da Cunha Belo M.G.S Ferreira, L. Guerra-Rosa, Corros. Sci. 45 (2003) 149. 


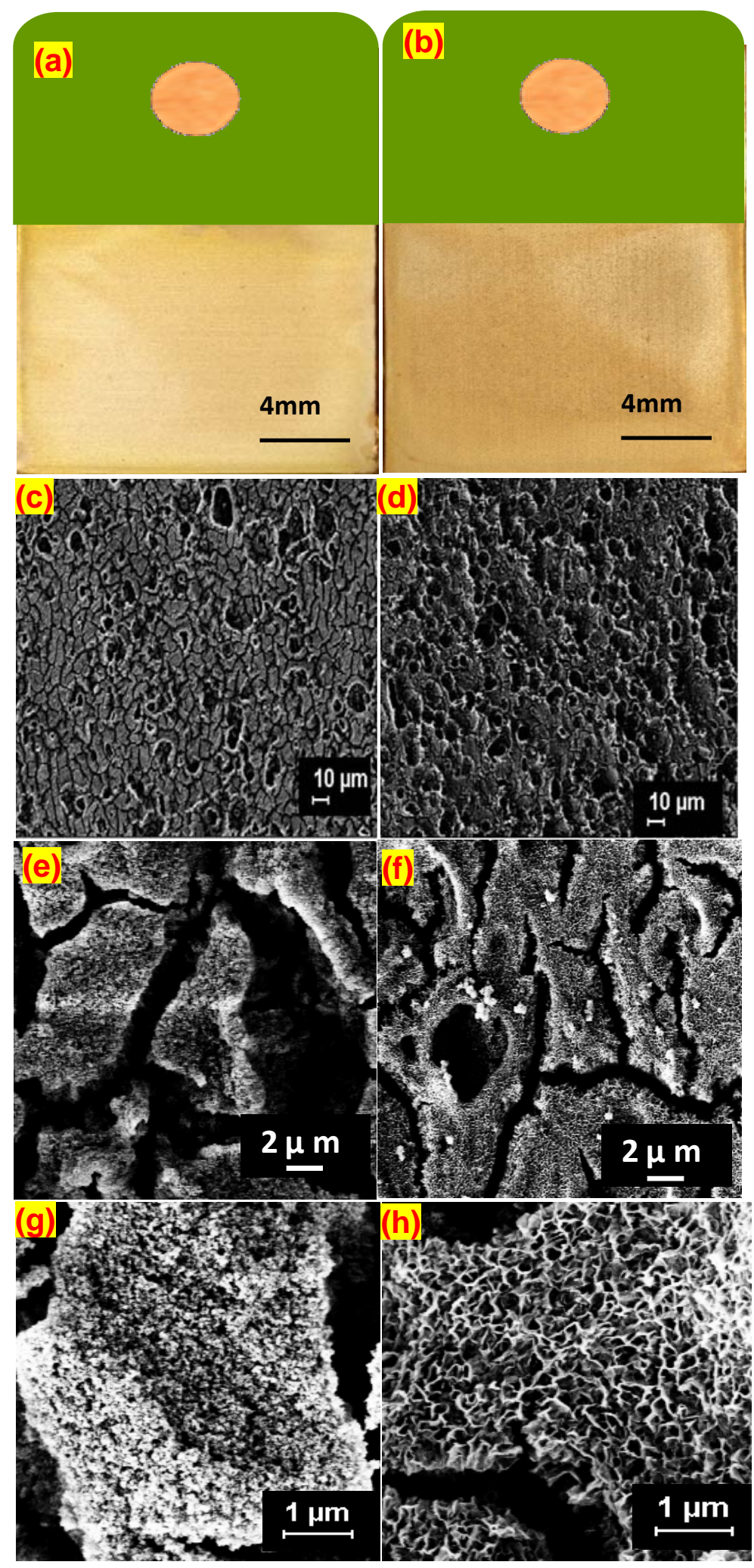

Fig.1 As prepared samples surface photographic and FESEM images of MnO (a,c, e and g) and $\operatorname{MnVO}(b, d, f$ and $h)$ with different magnifications. 

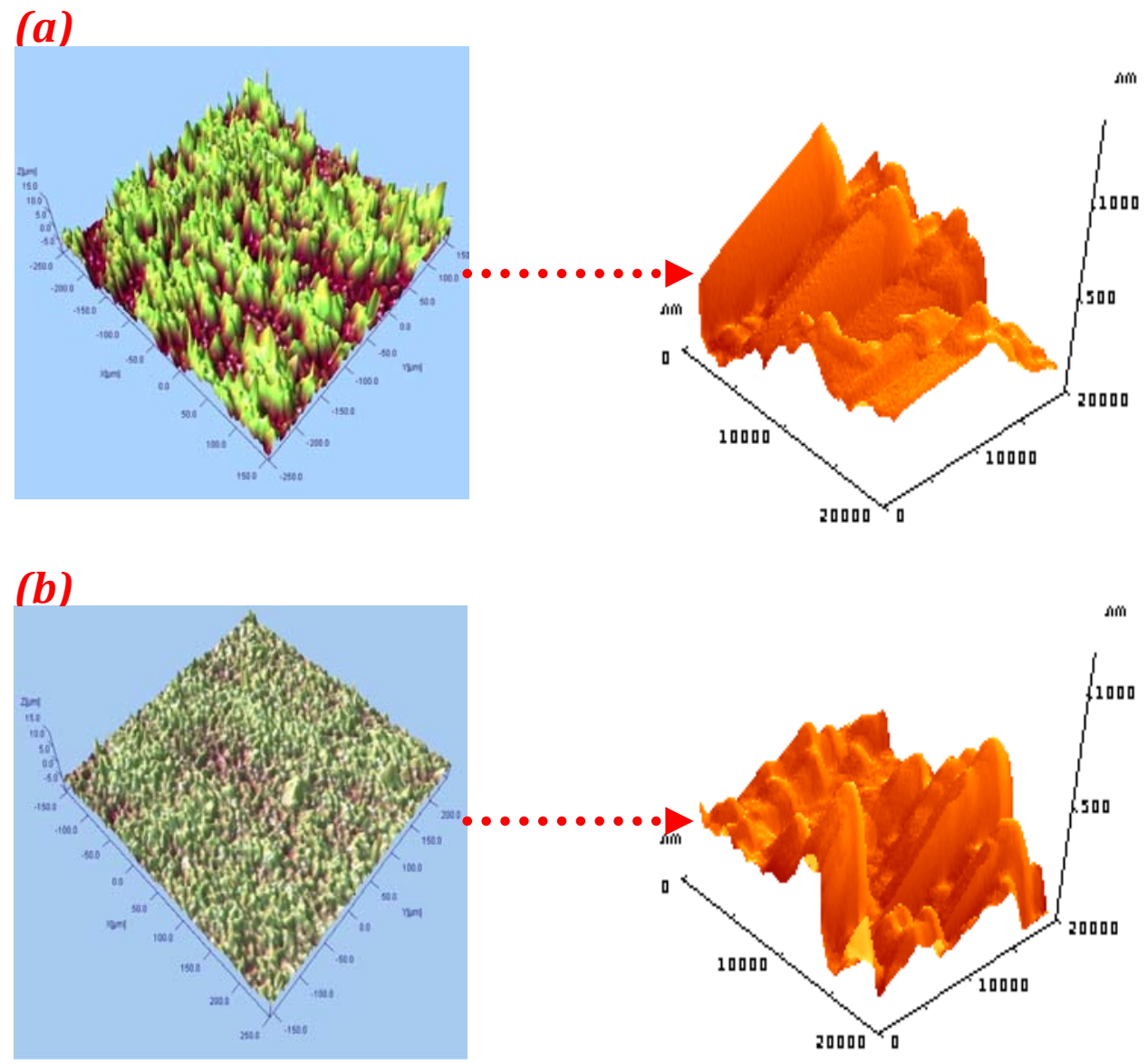

Fig.2 AFM surface topography of MnO (a) MnVO (b) 
(a)

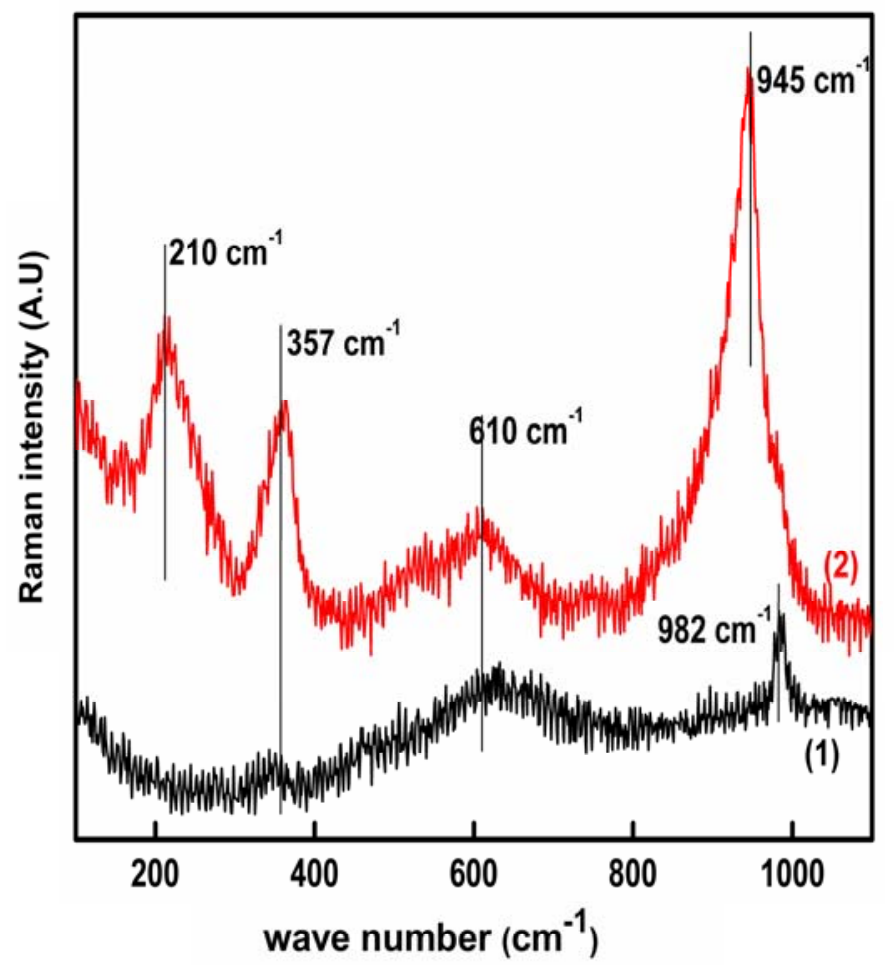

(b)

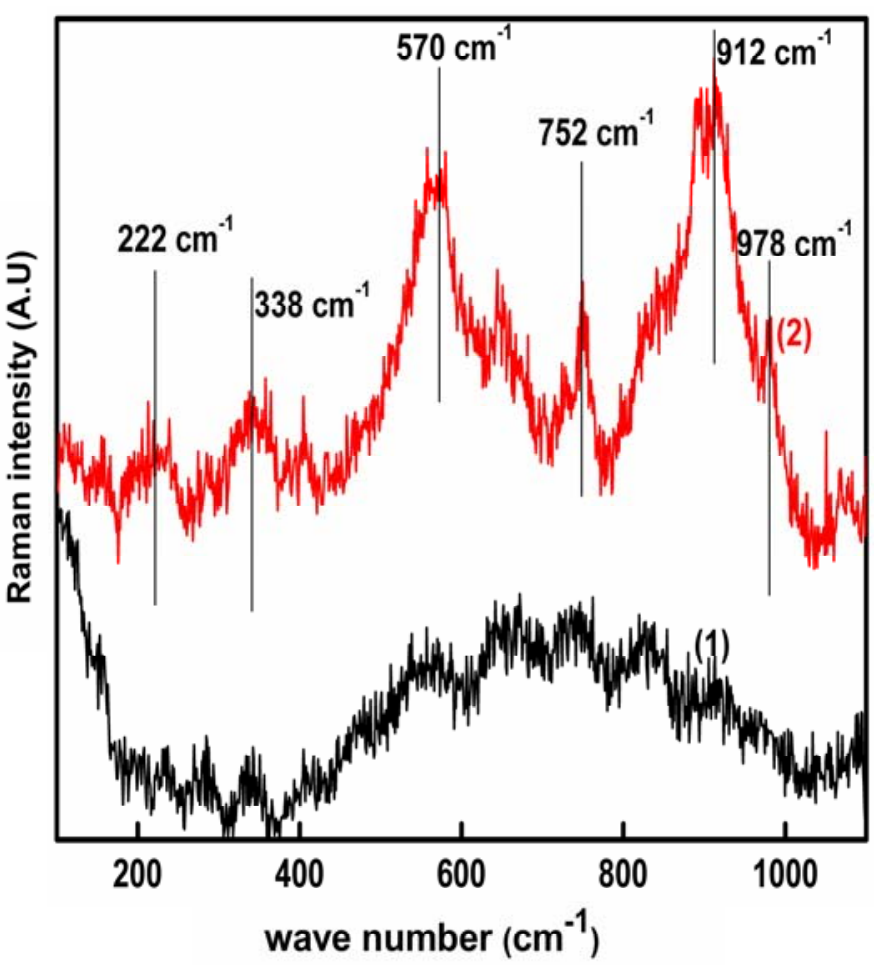

Fig.3 Average Raman spectra of as prepared (a), after $336 \mathrm{~h}$ polarization (b) for $\mathrm{MnO}$ (1) and $\mathrm{MnVO}(2)$ 
(a)
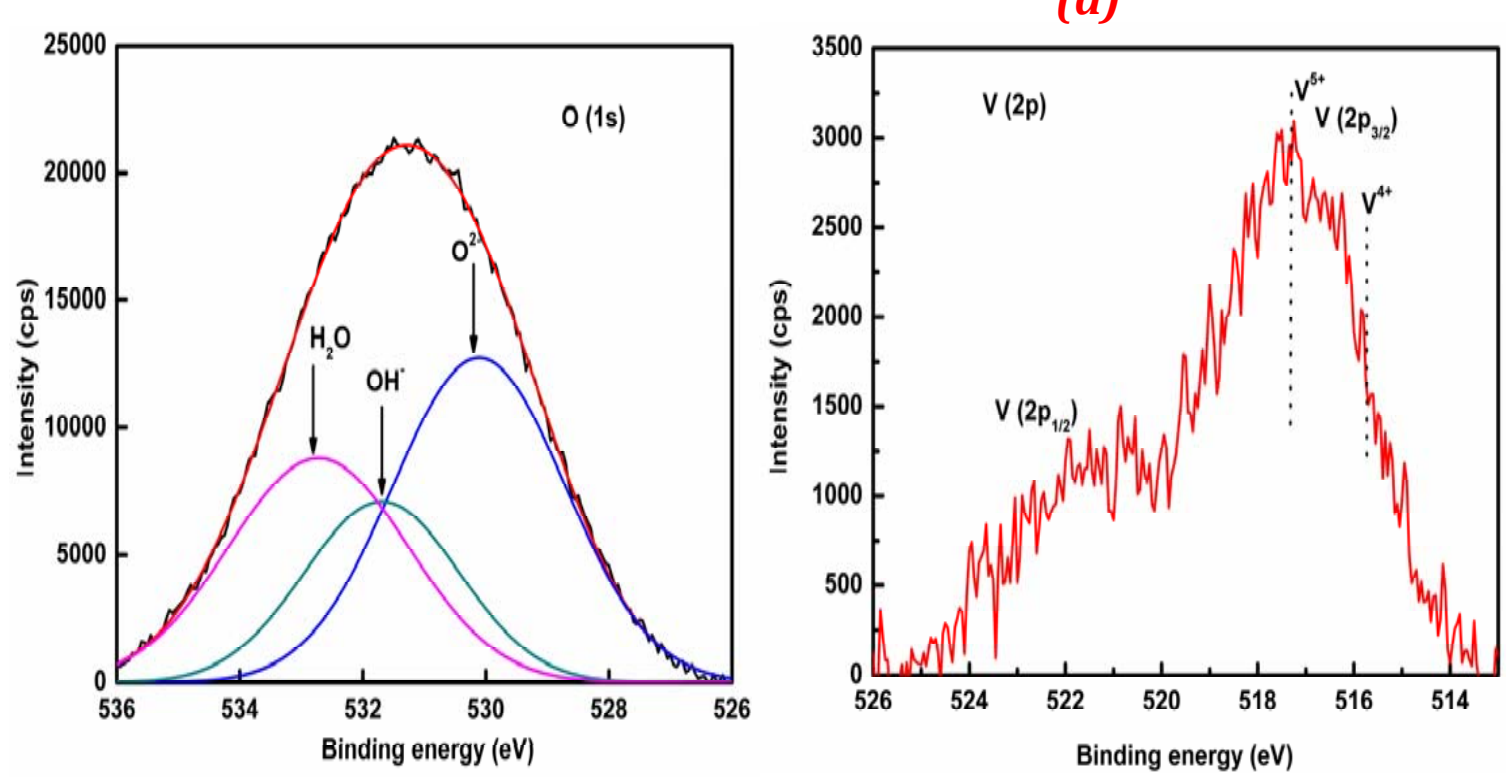

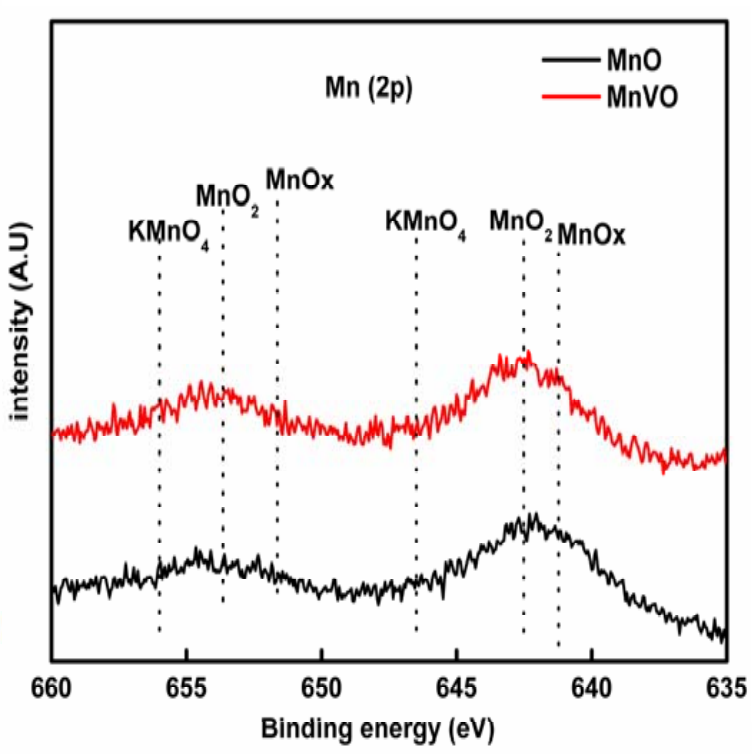

(b)
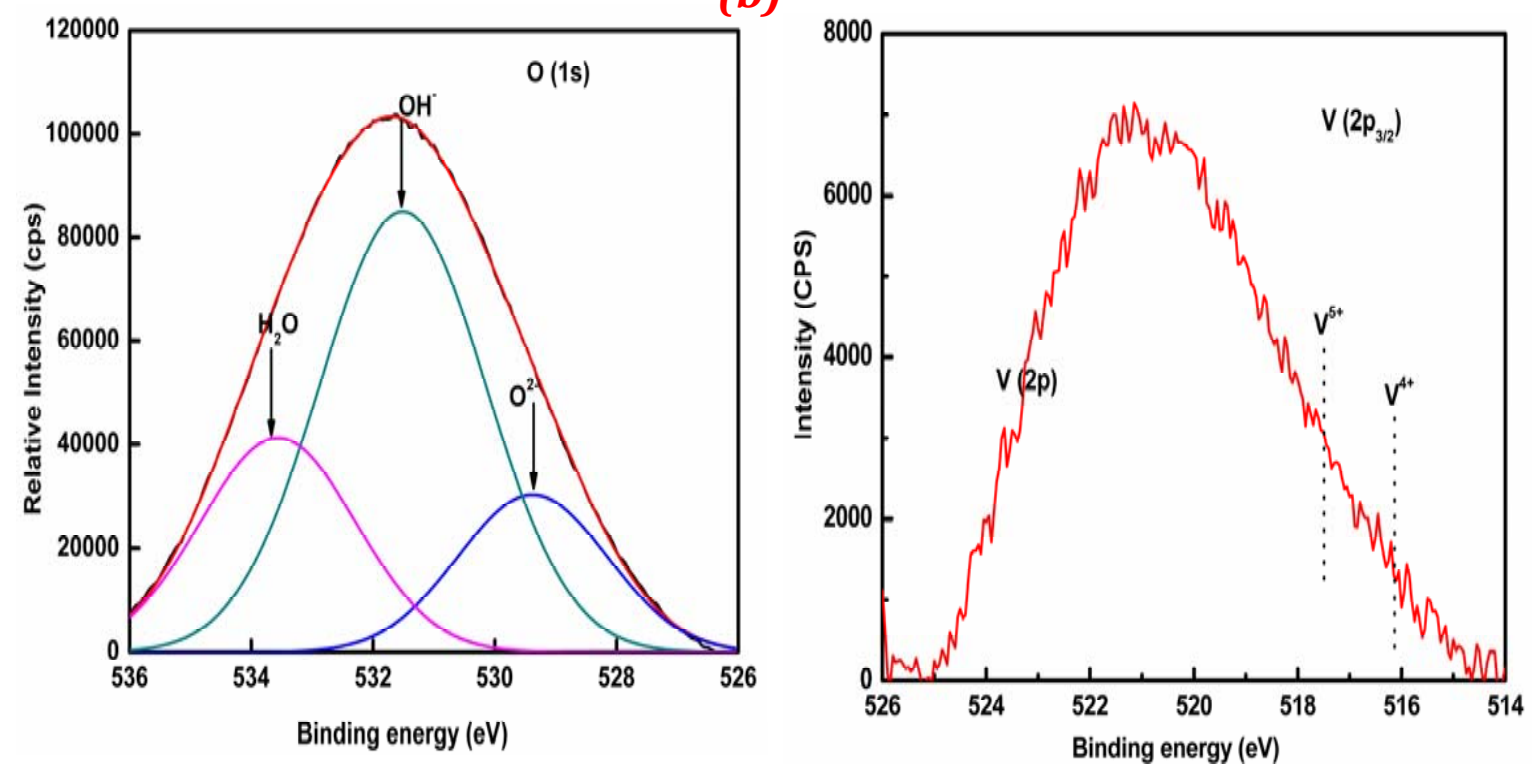

FIG.4 XPS spectra obtained for as prepared (a), after $336 \mathrm{~h}$ polarization (b) 

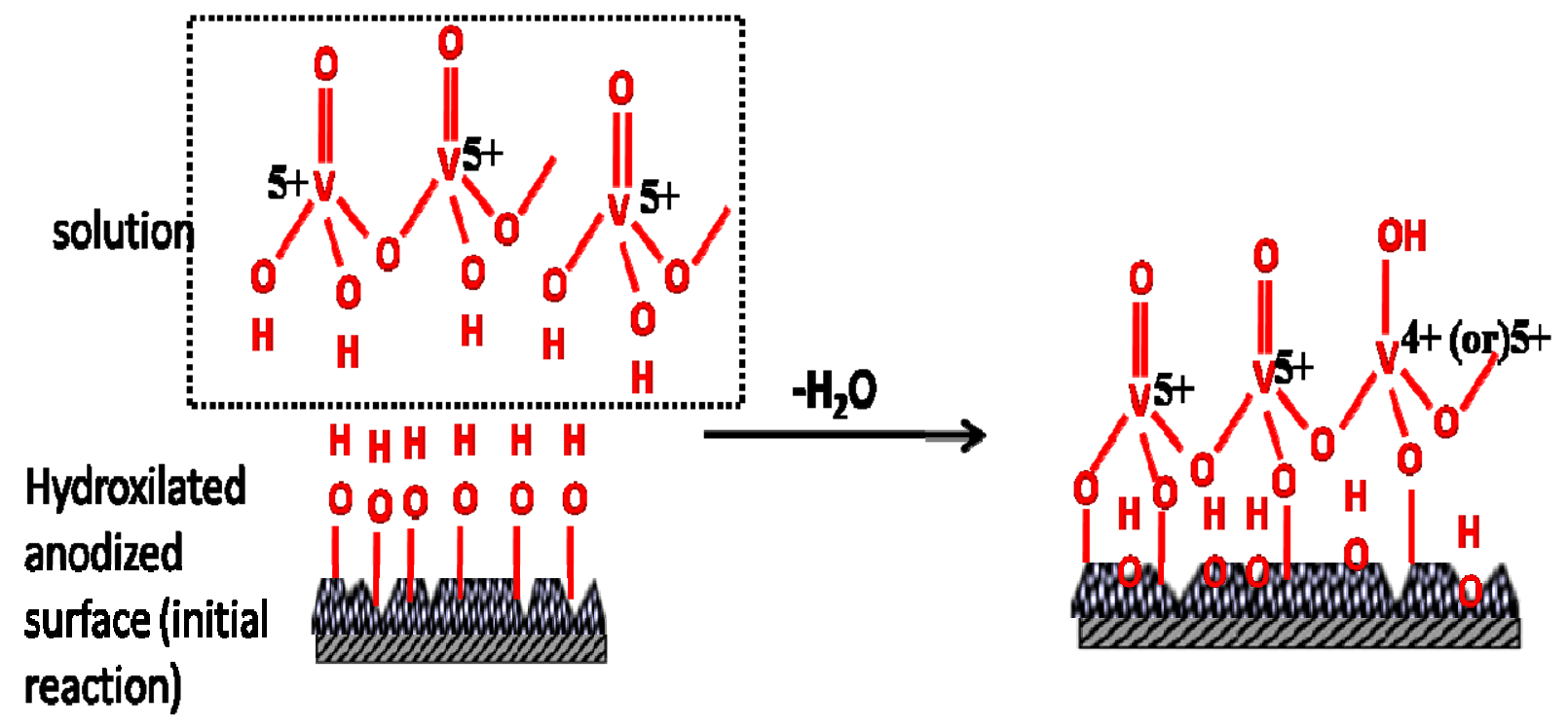

Fig.5 Chemical interaction of Vanadate with the anodized alumina during sealing 

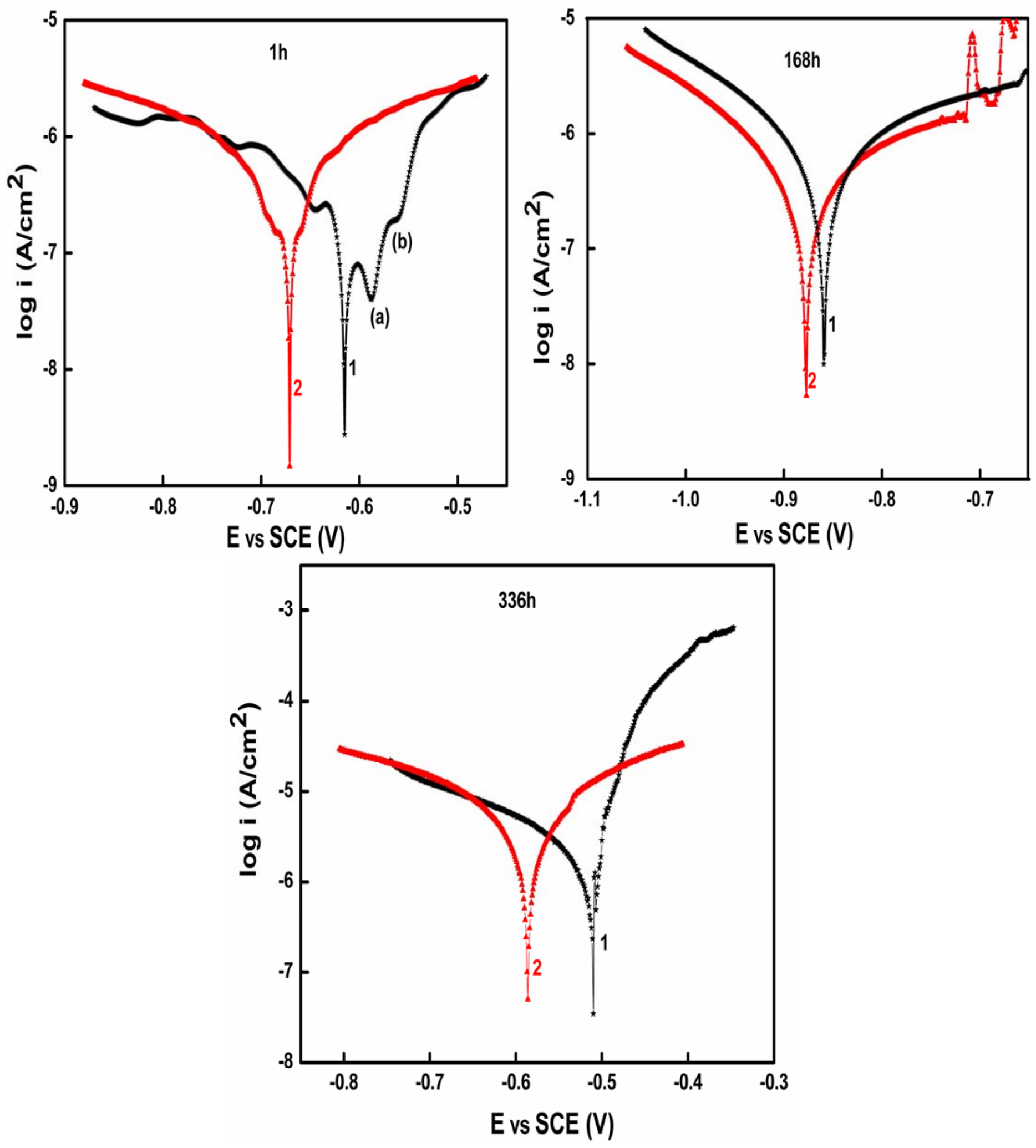

Fig.6 Tafel plot for MnO (1) and MnVO (2) up to $336 \mathrm{~h}$ of immersion in $3.5 \% \mathrm{NaCl}$ solution 

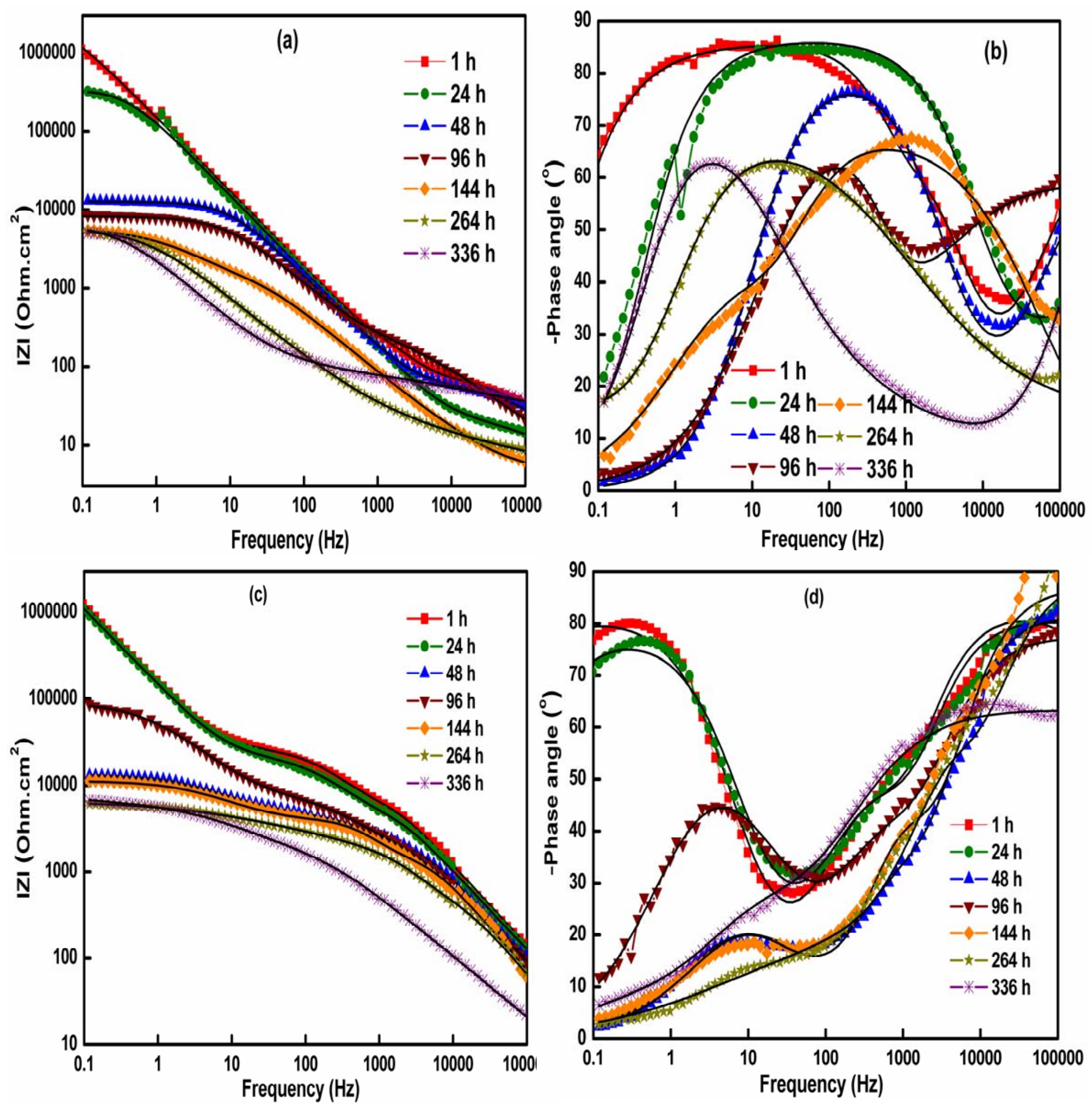

Fig.7 EIS-Bode plot for MnO, MnVO with fitting up to $336 \mathrm{~h}$ of immersion in 3.5\% $\mathrm{NaCl}$ solution 
(a)

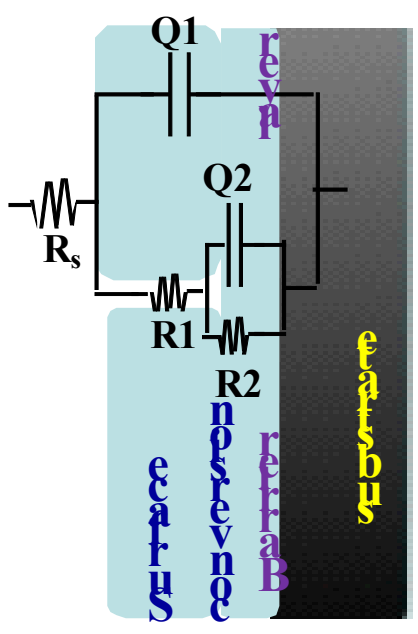

(b)

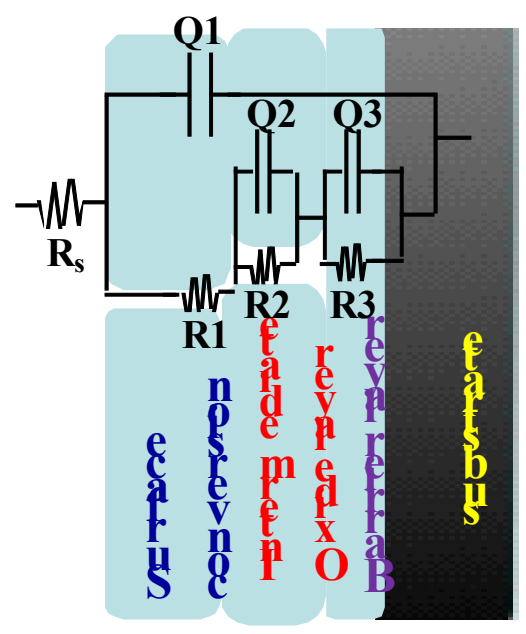

Fig.8 Electrochemical equivalent circuit for two (a) and three (b) time constants 


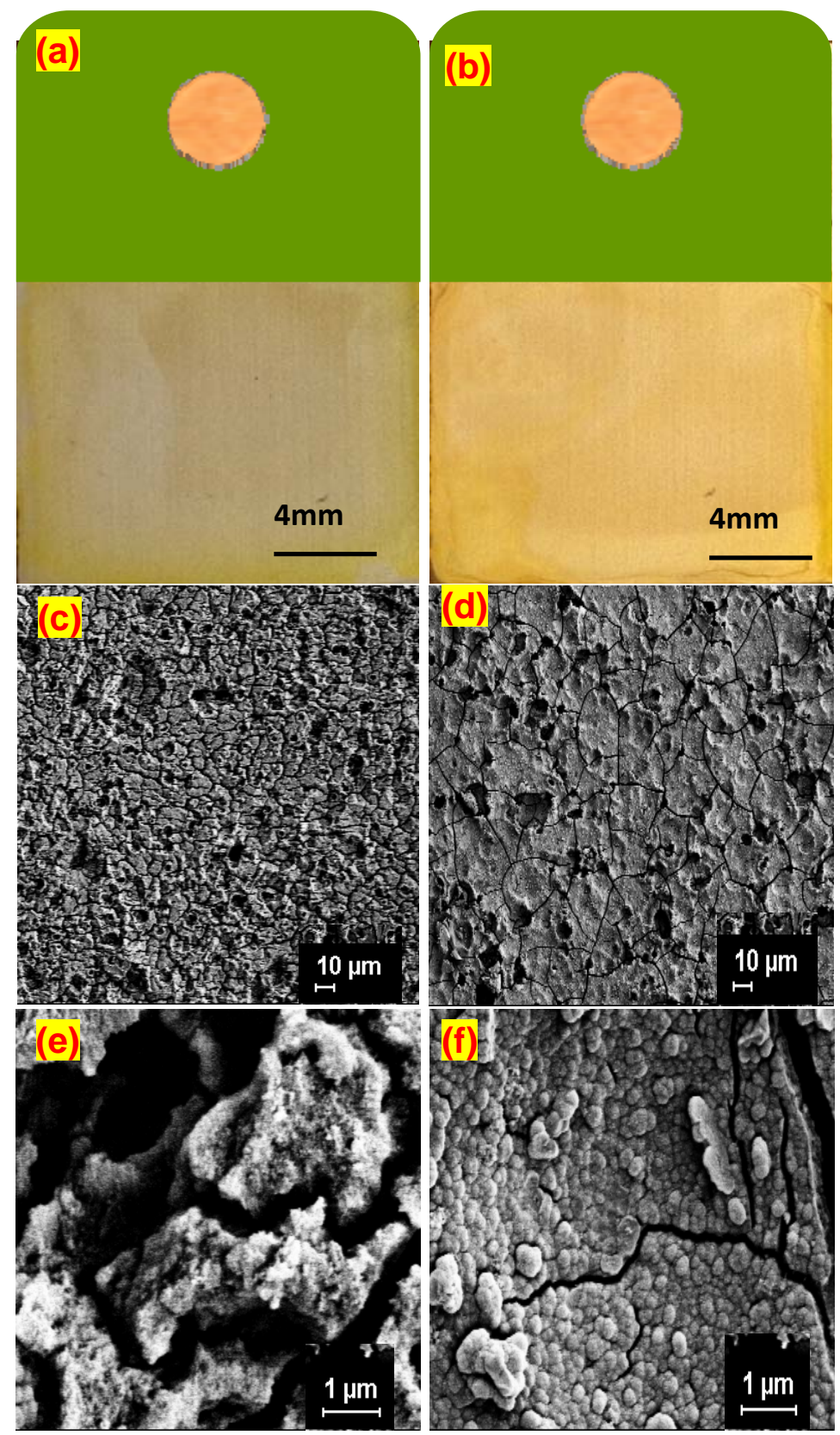

Fig.9 The surface photographic and FESEM images of MnO (a, c and e) and MnVO (b, d and $f$ ) at different magnifications after $168 \mathrm{~h}$ neutral salt spray exposure 


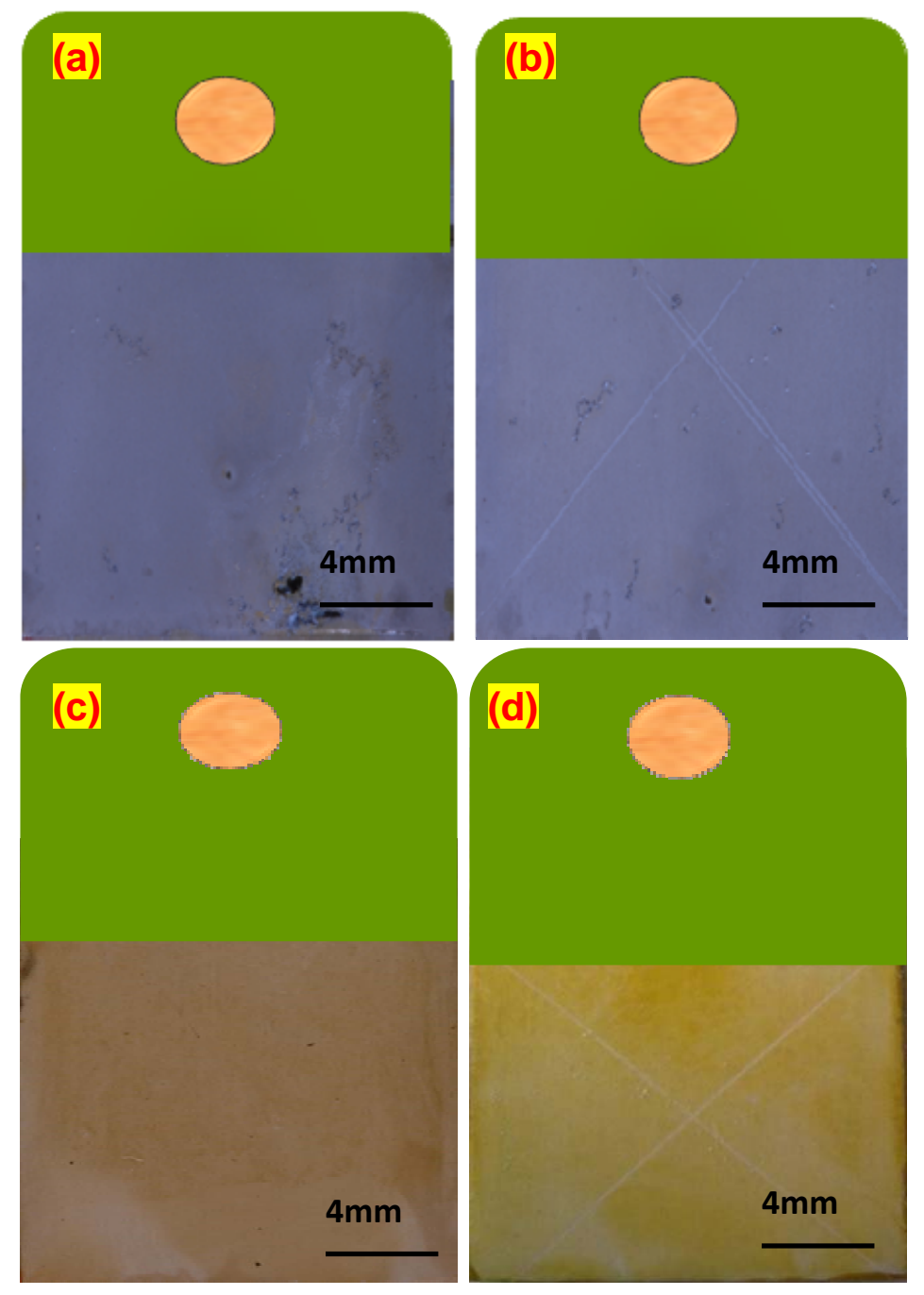

Fig.10 The surface photographic and FESEM images of with and without cross hatch of MnO (a and b) and MnVO (c and d) after $2000 \mathrm{~h}$ of neutral salt spray exposure 
Table 1

Compositional analysis of as prepared $\mathrm{MnO}$ and $\mathrm{MnVO}$ specimens by EDAX analysis.

\begin{tabular}{|c|c|c|c|c|c|c|c|}
\hline \multirow{2}{*}{$\begin{array}{c}\text { Specimen } \\
\text { details }\end{array}$} & \multicolumn{6}{|c|}{ Composition (at.\%) } \\
\cline { 2 - 7 } & $\mathrm{O}$ & $\mathrm{Al}$ & $\mathrm{Fe}$ & $\mathrm{Cu}$ & $\mathrm{Mg}$ & $\mathrm{Mn}$ & $\mathrm{V}$ \\
\hline MnO & 70.6 & 28.5 & 0.20 & 0.02 & 0.21 & 0.32 & - \\
\hline MnVO & 64.10 & 22.80 & 0.10 & 0.01 & 0.35 & 0.76 & 11.00 \\
\hline
\end{tabular}




\section{Table 2}

The surface roughness analysis of $\mathrm{PO}, \mathrm{MnO}$ and $\mathrm{MnVO}$ specimens by Atomic force microscopy.

\begin{tabular}{|c|c|c|c|}
\hline specimens & $\begin{array}{c}\text { Average } \\
\text { roughness } \mathbf{R}_{\mathbf{a}} \\
(\boldsymbol{\mu m})\end{array}$ & $\begin{array}{c}\text { Average } \\
\text { valley depth } \\
(\boldsymbol{\mu m})\end{array}$ & $\begin{array}{c}\text { Average } \\
\text { peak height } \\
(\boldsymbol{\mu m})\end{array}$ \\
\hline PO & 3.1 & 32 & 1.0 \\
\hline MnO & 2.6 & 8.9 & 3.1 \\
\hline MnVO & 0.77 & 8.2 & 1.0 \\
\hline
\end{tabular}




\section{Table 3}

The XPS quantitative results of as-prepared $\mathrm{MnO}$ and MnVO specimens.

\begin{tabular}{|c|c|c|c|c|c|c|}
\hline \multirow{2}{*}{$\begin{array}{c}\text { Specimen } \\
\text { details }\end{array}$} & \multirow{2}{*}{$\begin{array}{c}\text { Sputtering } \\
\text { condition }\end{array}$} & \multicolumn{5}{|c|}{ Composition (at.\%) } \\
\cline { 3 - 7 } & & O & Al & S & Mn & V \\
\hline \multirow{2}{*}{ MnO } & Before & 63.8 & 31.3 & 2.5 & 2.3 & - \\
\cline { 2 - 8 } & After & 60.2 & 35.0 & 0.8 & 3.9 & - \\
\hline \multirow{2}{*}{ MnVO } & Before & 87.5 & 4.9 & 0.5 & 3.3 & 3.6 \\
\cline { 2 - 7 } & After & 84.3 & 9.4 & - & 5.5 & 0.6 \\
\hline
\end{tabular}




\section{Table .4}

The potentiodynamic polarization result for $\mathrm{MnO}$ and $\mathrm{MnVO}$ after different duration of immersion into $3.5 \% \mathrm{NaCl}$ solution.

\begin{tabular}{|l|l|l|l|l|l|l|}
\hline \multirow{2}{*}{ Parameters } & \multicolumn{3}{|c|}{ MnO } & \multicolumn{3}{c|}{ MnVO } \\
\cline { 2 - 7 } & $\mathbf{1 ~ h}$ & $\mathbf{1 6 8 h}$ & $\mathbf{3 3 6}$ h & $\mathbf{1 ~ h}$ & $\mathbf{1 6 8 h}$ & $\mathbf{3 3 6}$ h \\
\hline $\mathrm{E}_{\text {corr }}(\mathrm{V})$ & -0.62 & -0.86 & -0.51 & -0.67 & -0.88 & -0.58 \\
\hline $\mathrm{i}_{\text {corr }}\left(\mu \mathrm{A} / \mathrm{cm}^{2}\right)$ & 0.41 & 0.63 & 5.08 & 0.52 & 0.43 & 5.2 \\
\hline $\begin{array}{l}\text { Corrosion rate } \\
\text { (mmpy) }\end{array}$ & 0.004 & 0.006 & 0.022 & 0.005 & 0.004 & 0.055 \\
\hline
\end{tabular}


Table .5

Compositional analysis of $\mathrm{MnO}$ and $\mathrm{MnVO}$ specimens by EDAX after $336 \mathrm{~h}$ polarization.

\begin{tabular}{|c|c|c|c|c|c|c|c|}
\hline \multirow{2}{*}{$\begin{array}{c}\text { Specimen } \\
\text { details }\end{array}$} & \multicolumn{7}{|c|}{ Composition (at. \%) } \\
\cline { 2 - 8 } & O & Al & Cu & Mg & Mn & V & W \\
\hline MnO & 65.83 & 31.5 & 0.34 & 0.35 & 0.10 & - & - \\
\hline MnVO & 70.00 & 27.5 & 0.20 & 0.15 & - & 1.01 & - \\
\hline
\end{tabular}


Table .6

Equivalent circuit parameters of $\mathrm{MnO}$ specimen by EIS up to $336 \mathrm{~h}$.

\begin{tabular}{|c|c|c|c|c|c|c|c|c|c|c|}
\hline $\begin{array}{c}\text { Sample } \\
\text { details }\end{array}$ & $\begin{array}{c}\text { Immersi } \\
\text { on time } \\
\text { (h) }\end{array}$ & $\begin{array}{c}Q_{1} \\
\left(\mu S s^{n}\right. \\
\left./ \mathbf{c m}^{2}\right)\end{array}$ & $n_{1}$ & $\begin{array}{c}R_{1} \\
(\mathrm{k} \Omega- \\
\left.\mathrm{cm}^{2}\right)\end{array}$ & $\begin{array}{c}Q_{2} \\
(\mu S \\
\left.s^{n} / \mathbf{c m}^{2}\right)\end{array}$ & $n_{2}$ & $\begin{array}{c}R_{2} \\
(\mathrm{k} \Omega- \\
\left.\mathrm{cm}^{2}\right)\end{array}$ & $\begin{array}{c}Q_{3} \\
(\mu S \\
\left.\mathbf{s}^{\mathrm{n}} / \mathbf{c m}^{2}\right)\end{array}$ & $n_{3}$ & $\begin{array}{c}R_{3} \\
(\mathrm{k} \Omega- \\
\left.\mathrm{cm}^{2}\right)\end{array}$ \\
\hline \multirow{7}{*}{ MnO } & 1 & 2.81 & 0.69 & 0.08 & 1.17 & 0.94 & 1082.00 & - & - & - \\
\hline & 24 & 11.59 & 0.61 & 0.06 & 1.21 & 0.96 & 539.50 & - & - & - \\
\hline & 48 & 0.55 & 0.81 & 0.05 & 1.77 & 0.92 & 12.71 & - & - & - \\
\hline & 96 & 5.71 & 0.67 & 0.50 & 0.63 & 0.99 & 9.14 & - & - & - \\
\hline & 144 & 0.12 & 0.85 & 0.62 & 0.43 & 0.69 & 8.30 & - & - & - \\
\hline & 264 & 0.11 & 0.60 & 0.80 & 0.05 & 0.51 & 7.53 & - & - & - \\
\hline & 336 & 0.12 & 0.80 & 0.17 & 0.08 & 0.91 & 0.04 & 0.77 & 0.89 & 5.74 \\
\hline
\end{tabular}


Table .7

Equivalent circuit parameters of MnVO specimen by EIS up to $336 \mathrm{~h}$.

\begin{tabular}{|c|c|c|c|c|c|c|c|c|c|c|}
\hline $\begin{array}{l}\text { Sample } \\
\text { details }\end{array}$ & $\begin{array}{c}\text { Immersion } \\
\text { time (h) }\end{array}$ & $\begin{array}{c}Q_{1} \\
(\mu S \\
s^{n} \\
\left./ \mathbf{c m}^{2}\right)\end{array}$ & $n_{1}$ & $\begin{array}{c}R_{1} \\
(\mathrm{k} \Omega- \\
\left.\mathrm{cm}^{2}\right)\end{array}$ & $\begin{array}{c}Q_{2}(\mu S \\
\left.s^{n} / \mathrm{cm}^{2}\right)\end{array}$ & $n_{2}$ & $\begin{array}{c}R_{2} \\
(\mathrm{k} \Omega- \\
\left.\mathrm{cm}^{2}\right)\end{array}$ & $\begin{array}{c}Q_{3}(\mu S \\
\left.s^{n} / \mathbf{c m}^{2}\right)\end{array}$ & $n_{3}$ & $\begin{array}{c}R_{\mathbf{3}} \\
(\mathrm{k} \Omega- \\
\left.\mathbf{c m}^{2}\right)\end{array}$ \\
\hline \multirow{7}{*}{ MnVO } & 1 & 0.025 & 0.95 & 3.40 & 1.20 & 0.91 & 21.2 & 0.14 & 0.85 & 2178.00 \\
\hline & 24 & 0.030 & 0.96 & 2.42 & 1.35 & 0.88 & 0.23 & 0.82 & 0.82 & 1712.00 \\
\hline & 48 & 0.031 & 0.98 & 1.36 & 11.78 & 0.70 & 3.00 & 0.44 & 0.83 & 110.14 \\
\hline & 96 & 0.086 & 0.93 & 1.32 & 3.52 & 0.77 & 4.93 & 0.53 & 0.81 & 11.04 \\
\hline & 144 & 0.030 & 0.9 & 1.06 & 12.32 & 0.72 & 7.65 & 0.14 & 0.97 & 10.05 \\
\hline & 264 & 0.055 & 0.96 & 1.17 & 0.28 & 0.42 & 0.25 & 0.04 & 0.98 & 8.52 \\
\hline & 336 & 0.22 & 0.67 & 1.17 & 0.41 & 0.73 & 1.54 & 0.05 & 0.62 & 8.03 \\
\hline
\end{tabular}




\section{Table .8}

Calculation of damage function (D) parameter for $\mathrm{MnO}$ and $\mathrm{MnVO}$ specimens from electrochemical impedance spectroscopy up to $336 \mathrm{~h}$.

\begin{tabular}{|c|c|c|c|c|}
\hline \multirow[b]{2}{*}{$\begin{array}{c}\text { Immersion } \\
\text { time (h) }\end{array}$} & \multicolumn{2}{|c|}{ MnO } & \multicolumn{2}{|c|}{ MnVO } \\
\hline & $\begin{array}{c}|\mathrm{Z}|_{0.1 \mathrm{~Hz}} \\
\left(\Omega-\mathrm{cm}^{2}\right)\end{array}$ & (D) & $\begin{array}{c}|\mathrm{Z}|_{0.1 \mathrm{~Hz}} \\
\left(\Omega-\mathrm{cm}^{2}\right)\end{array}$ & (D) \\
\hline 1h & 1199708 & $0.52 \pm 0.1$ & 1265509 & $0.05 \pm 0.01$ \\
\hline $24 \mathrm{~h}$ & 319420 & $1.39 \pm 0.2$ & 1119062 & $1.93 \pm 0.1$ \\
\hline $48 \mathrm{~h}$ & 12740 & $0.19 \pm 0.05$ & 13118 & $-0.80 \pm 0.1$ \\
\hline $96 \mathrm{~h}$ & 8220 & $0.18 \pm 0.1$ & 82946 & $0.87 \pm 0.07$ \\
\hline $144 \mathrm{~h}$ & 5439 & $0.01 \pm 0.01$ & 11100 & $0.25 \pm 0.05$ \\
\hline $216 \mathrm{~h}$ & $\begin{array}{l}5288 \\
5490\end{array}$ & $-0.02 \pm 0.001$ & $\begin{array}{l}6143 \\
6754\end{array}$ & $-0.04 \pm 0.01$ \\
\hline
\end{tabular}

